Brief Report

\title{
An Abiotic Stress Responsive U-Box E3 Ubiquitin Ligase Is Involved in OsGI-Mediating Diurnal Rhythm Regulating Mechanism
}

\author{
Yo-Han Yoo, Xu Jiang and Ki-Hong Jung * (1) \\ Graduate School of Biotechnology \& Crop Biotech Institute, Kyung Hee University, Yongin 17104, Korea; \\ directorhan@khu.ac.kr (Y.-H.Y.); kangwuk97@khu.ac.kr (X.J.) \\ * Correspondence: khjung2010@khu.ac.kr
}

Received: 21 July 2020; Accepted: 17 August 2020; Published: 20 August 2020

\begin{abstract}
The plant U-box (PUB) protein is the E3 ligase that plays roles in the degradation or post-translational modification of target proteins. In rice, 77 U-box proteins were identified and divided into eight classes according to the domain configuration. We performed a phylogenomic analysis by integrating microarray expression data under abiotic stress to the phylogenetic tree context. Real-time quantitative reverse transcription polymerase chain reaction (qRT-PCR) expression analyses identified that eight, twelve, and eight $P U B$ family genes are associated with responses to drought, salinity, and cold stress, respectively. In total, 16 genes showed increased expression in response to three abiotic stresses. Among them, the expression of OsPUB2 in class II and OsPUB33, OsPUB39, and OsPUB41 in class III increased in all three abiotic stresses, indicating their involvement in multiple abiotic stress regulation. In addition, we identified the circadian rhythmic expression for three out of 16 genes responding to abiotic stress through meta-microarray expression data analysis. Among them, OsPUB4 is predicted to be involved in the rice GIGANTEA (OsGI)-mediating diurnal rhythm regulating mechanism. In the last, we constructed predicted protein-protein interaction networks associated with OsPUB4 and OsGI. Our analysis provides essential information to improve environmental stress tolerance mediated by the PUB family members in rice.
\end{abstract}

Keywords: abiotic stress; diurnal regulation; OsGI; rice; U-box E3 ligase

\section{Introduction}

Ubiquitination is a protein degradation system that regulates the amount of intracellular accumulation of signaling substances by selectively degrading certain proteins [1]. Especially in plants, various hormone signaling mechanisms, development, biotic, and abiotic stress signaling mechanisms have been reported to be closely related to ubiquitination [2,3]. Ubiquitin is a small $8-\mathrm{kDa}$ protein in all eukaryotes. It is attached to specific proteins by the three enzymes $\mathrm{Ub}$-activating enzyme (E1), Ub-conjugating enzyme (E2) and Ub-ligase (E3). Specific proteins that are subsequently polyubiquitinated are degraded by the $26 \mathrm{~S}$ proteasome [4,5]. Among these, E3 ligase plays a major role in determining the specificity of the substrate and is largely divided into single-subunit E3 ligase and multi-subunit E3 ligase depending on the structure.

The single-subunit E3 ligase acts as an E3 ligase by itself, without any additional protein [6]. Single-subunit E3 ligase is subdivided into three proteins according to the domain: RING (for Really Interesting New Gene), U-box, and HECT (for Homology to E6-AP carboxyl terminus). Interestingly, other single-subunit E3 ligases exist in similar numbers among eukaryotes, but the number of U-box E3 ligases in plants is higher than in other eukaryotes. For example, 21 and 2 U-box E3 ligases were found in human and yeast $[7,8]$, while Arabidopsis and rice were known to be 64 and 77 , respectively $[9,10]$. 
Thus, the diversity of plant U-box genes suggests that the U-box domain may play an important role in performing plant-specific intracellular processes.

The circadian clock is an evolutionary system adapted to fluctuating environmental changes in the earth [11]. In particular, circadian clocks of immovable plants have more authority than animals and participate in various developmental processes [12]. The circadian clock is divided into an input that accepts the external environment signal, an oscillator that generates the rhythm according to the change cycle of the external environment, and an output that is controlled by this oscillator [13]. The most representative function of the output in the plant circadian clock is flowering. In other words, the circadian clock of the plant recognizes the photoperiod and determines the timing of the flowering [14]. For example, Arabidopsis induces the degradation of CYCLING DOF FACTOR 1 (CDF1), which prevents the expression of CONSTANS (CO), an important gene for flowering, by inducing the binding between two proteins of GIGANTEA (GI) and FLAVIN-BINDING, KELCH REPEAT, F-BOX 1 (FKF1) in the long-day condition. However, in a short-day condition, the binding between the two proteins GI and FKF1 is decreased, so that the expression of $C O$ is kept low and the flowering time is delayed [15].

In rice, 77 U-box E3 ligase genes are known, of which only six genes have been reported [16-20]. In other words, many rice U-box E3 ligase genes have not yet been studied, and phenotypic interference due to functional redundancy may be one of the reasons [21]. Therefore, we analyzed transcriptome data using the phylogenomics tool and tried to obtain information on the environmental response characteristics of individual genes. This study comprehensively analyzed the expression characteristics in response to abiotic stress (drought, salinity, and cold) and the circadian clock which have not been studied in the previous genome-wide PUB family. Based on this, we will provide important fundamental data for studying the functions of individual PUB gene family.

\section{Materials and Methods}

\subsection{Multiple Alignment and Phylogenetic Analysis}

To perform our phylogenetic analysis of the PUB family, we used the protein sequences of 77 PUB genes identified in a previous global analysis of the rice PUB family [10]. The protein sequences for our phylogenomic analysis were downloaded from the Rice Genome Annotation Project Website [22]. After multiple-alignment of those sequences with ClustalX [23], we generated a phylogenetic tree using the Neighbor-Joining method, as incorporated in the MEGA5 tool kit for phylogenetic analysis [24].

\subsection{Meta-Analysis of Gene Expression Data and Heatmap Development}

Affymetric- and agilent-microarray data (GSE6901, GSE36040 and GSE38023), and RNA-seq data (GSE92989) were downloaded from the NCBI Gene Expression Omnibus (GEO, http://www.ncbi.nlm. nih.gov/geo/). We then uploaded the normalized expression data to the Multi Experiment Viewer and visualized the data via heatmaps (http://www.tm4.org/mev.html).

\subsection{Plant Materials and Abiotic Stress Treatment}

Rice (O. sativa L.cv. Dongjin) seeds were germinated on the Murashige Skoog medium for 14 days at $28{ }^{\circ} \mathrm{C}$. Subsequently, the seedlings were washed with sterilized water to completely remove the agar and were air-dried for $0,2,6$, and $12 \mathrm{~h}$ at $28^{\circ} \mathrm{C}$ for drought stress treatment [25]. To simulate salinity stress, we exposed 14-day-old plants to $200 \mathrm{mM} \mathrm{NaCl}$ for $0,2,6$, and $12 \mathrm{~h}$ at $28^{\circ} \mathrm{C}$ [26]. In the last, we exposed 14-day-old plants to $4{ }^{\circ} \mathrm{C} \pm 1{ }^{\circ} \mathrm{C}$ for $0,2,6$, and $12 \mathrm{~h}$ for cold stress treatment. The control plants remained at $28^{\circ} \mathrm{C}$. Leaves and roots of three plants were pooled for one biological replicate and each treatment had three biological repeats. 


\subsection{Plant Materials for Diurnal Rhythm}

To investigate the functional associations of PUB family members with the diurnal rhythm and OsGI (GIGANTEA)-mediating regulatory pathway, Wild-type (WT) plant and osgi mutant seeds (LOC_Os01g08700) were germinated on the Murashige Skoog medium for 7 days at $28{ }^{\circ} \mathrm{C}$ [27]. They were then transferred to individual pots and grown in an incubator (12-h light/12-h dark, $28^{\circ} \mathrm{C} / 22^{\circ} \mathrm{C}$ ) for 30 days. After that, their leaves were sampled at 2-h intervals for $24 \mathrm{~h}$.

\subsection{RNA Extraction and Real-Time Quantitative PCR}

Samples were frozen in liquid nitrogen and total RNAs were extracted using RNAiso Plus (Takara Bio, Kyoto, Japan). Using MMLV Reverse Transcriptase (Promega, Madison, WI, USA) and the oligo(dT) 15 primer, first-strand cDNA was synthesized as we recently reported [28,29]. For normalizing the amplified transcripts, we used a primer pair for rice ubiquitin 5 (OsUbi5/Os01g22490) [30]. All primers for these analyses are summarized in Table S1.

\subsection{Analysis of a Predicted Protein-Protein Interaction Network}

Using the STRING tool (https://version-10-5.string-db.org/) [31], we generated a hypothetical protein-protein interaction network involving E3 ubiquitin ligase, transcription factors (TFs), and flowering regulatory genes. The network was edited with the Cytoscape tool (https://cytoscape.org/; version 3.6.0) (The Cytoscape Consortium, New York, NY, USA) [32,33].

\section{Results and Discussion}

3.1. Integration of Abiotic Stress Expression Patterns with a Phylogenetic Tree Context of the Rice PUB Family Reveals the Key PUB Family Members for the Stress Responses

According to the recent report on the PUB family in rice, 77 estimated U-box proteins were identified through a whole-genome analysis algorithm and divided into eight classes according to the domain configuration (Figure 1 and Figure S1) [10]. We have constructed a phylogenetic tree using protein sequences for each of the five classes except I, VI, and VIII, which have only one or two genes in the eight classes. The expression of 77 genes was visualized using drought- and salinity-treated RNA-seq data (GSE92989) using seedling roots [26], and cold-treated microarray data (GSE6901 and GSE38023) from using seedling leaves. When the resultant microarray data were examined according to criteria where $t$-test $p$-values were $<0.01$ and upregulation showed a greater than 1 ( $\log _{2}$ scale)-fold change for control versus abiotic stress, we were able to identify 16 genes (Figure 1). The remaining genes in the heat-map were visualized in gray color. As a result, we identified eight (OsPUB2, OsPUB4, OsPUB5, OsPUB8, OsPUB33, OsPUB39, OsPUB41 and OsPUB67), twelve (OsPUB2, OsPUB3, OsPUB5, OsPUB6, OsPUB33, OsPUB39, OsPUB41, OsPUB46, OsPUB51, OsPUB63, OsPUB64 and OsPUB67), and eight (OsPUB2, OsPUB10, OsPUB33, OsPUB39, OsPUB41, OsPUB43, OsPUB46 and OsPUB64) upregulated genes under drought, salinity, and cold stress conditions $[25,26]$. Interestingly, expression of OsPUB2 in class II and OsPUB33, OsPUB39, and OsPUB41 in class III increased in all three abiotic stresses. In addition, most genes with increased expression in drought, salinity, and cold stress were included in classes II, III, and VII. These results indicate that among the 77 PUB families, there are pivotal classes and genes that respond to environmental stress.

\subsection{Real-Time Quantitative PCR Analysis Confirmed Expression Patterns in Response to Drought, Salt and} Cold Stresses of 16 PUB Family Genes in Rice

To confirm the global transcriptome data, we carried out quantitative reverse transcription polymerase chain reaction (qRT-PCR) analysis of PUB family genes in the drought, salinity, and cold stress conditions. Fourteen-day-old seedlings were treated with drought, salinity, and cold stress for 0 , 2,6 , and $12 \mathrm{~h}$, respectively. Root samples under drought and salinity stress and leaf samples under cold stress are collected for cDNA synthesis. 


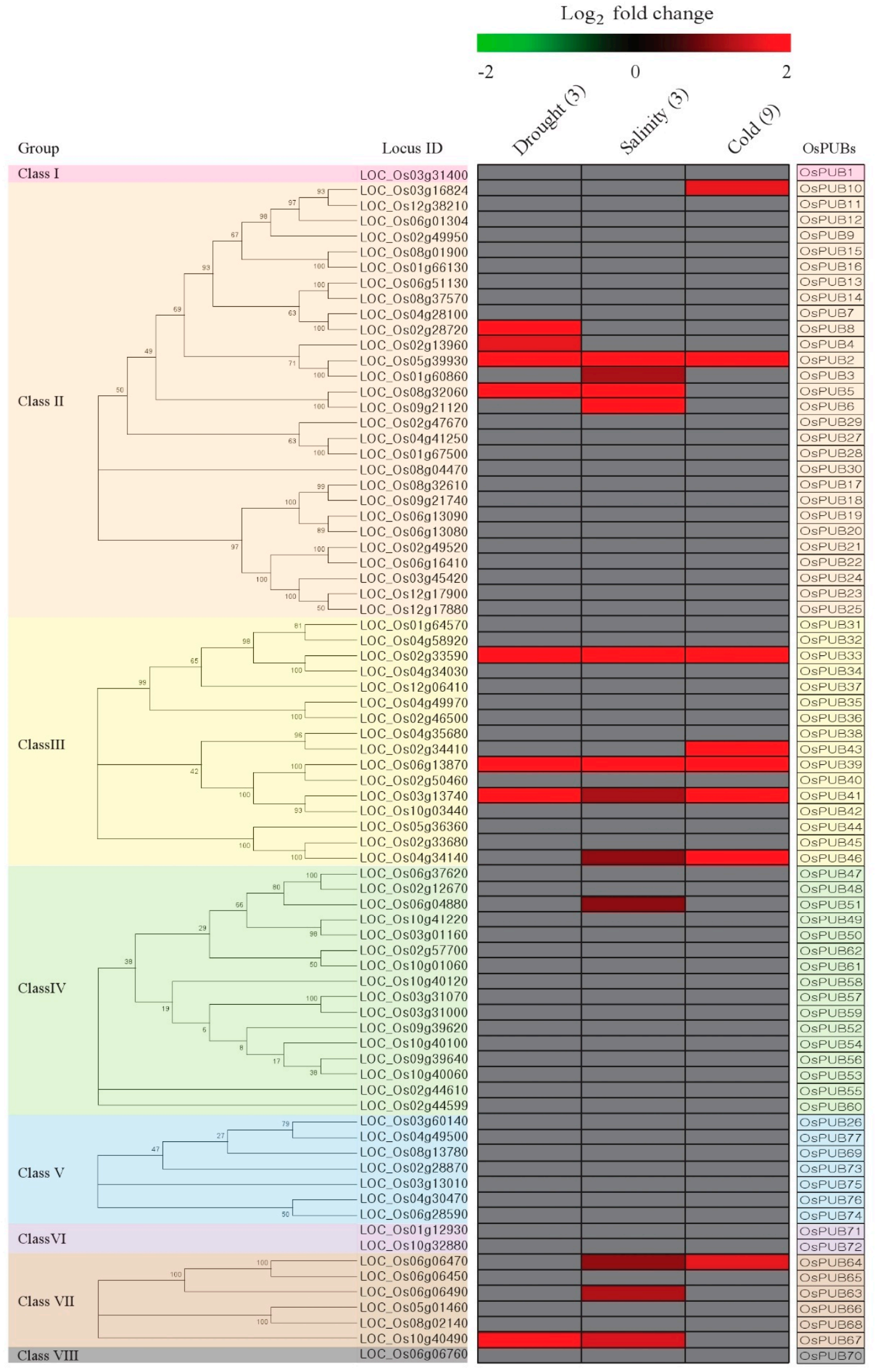

Figure 1. Meta-analysis of OsPUB genes expression patterns using drought- salinity- and cold-treated microarray data. On the left side of the heat-map is a phylogenetic tree for each class. Green, low level of $\log _{2}$ intensity; red, high level; gray, $t$-test $p$-value $>0.01$ or enrichment values of $<1\left(\log _{2}\right)$-fold. 
As the first step, we tested the expression of OsDREB1A, a drought and cold stress marker gene, for drought $(0,2,6$, and $12 \mathrm{~h})$ and cold $(0,2,6$, and $12 \mathrm{~h})$ stress samples, and of expression of OsbZIP23, a salt stress marker gene, for salt $(0,2,6$, and $12 \mathrm{~h})$ stress samples [34,35]. As expected, expressions of OsDREB1A and OsbZIP23 were significantly stimulated compared to the control at all tested time points of stress treatment (Figure 2), indicating that samples under drought, salt, and cold stress treatments are well qualified for the further differential expression analyses. To validate expression patterns of selected PUB genes, we chose a $2 \mathrm{~h}$ sample (salinity) and $12 \mathrm{~h}$ samples (drought and cold) out of the time series stress treatments showing stronger and more stable upregulation of marker genes. Subsequently, we confirmed that expressions of 16 PUB genes were significantly upregulated under drought, salinity and cold stresses (Figure 2). These results are in agreement with expression patterns analyzed using transcriptome data associated with abiotic stress.
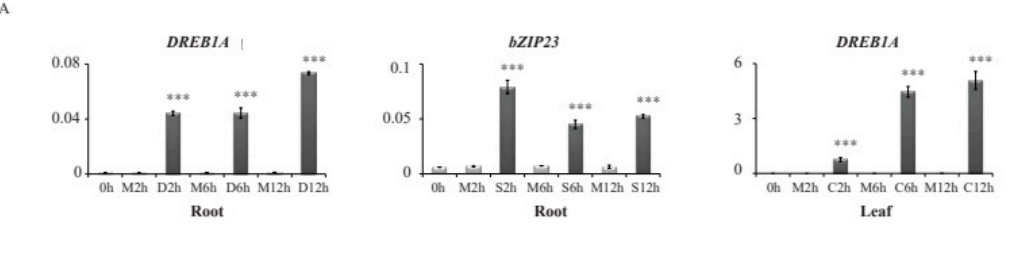

B
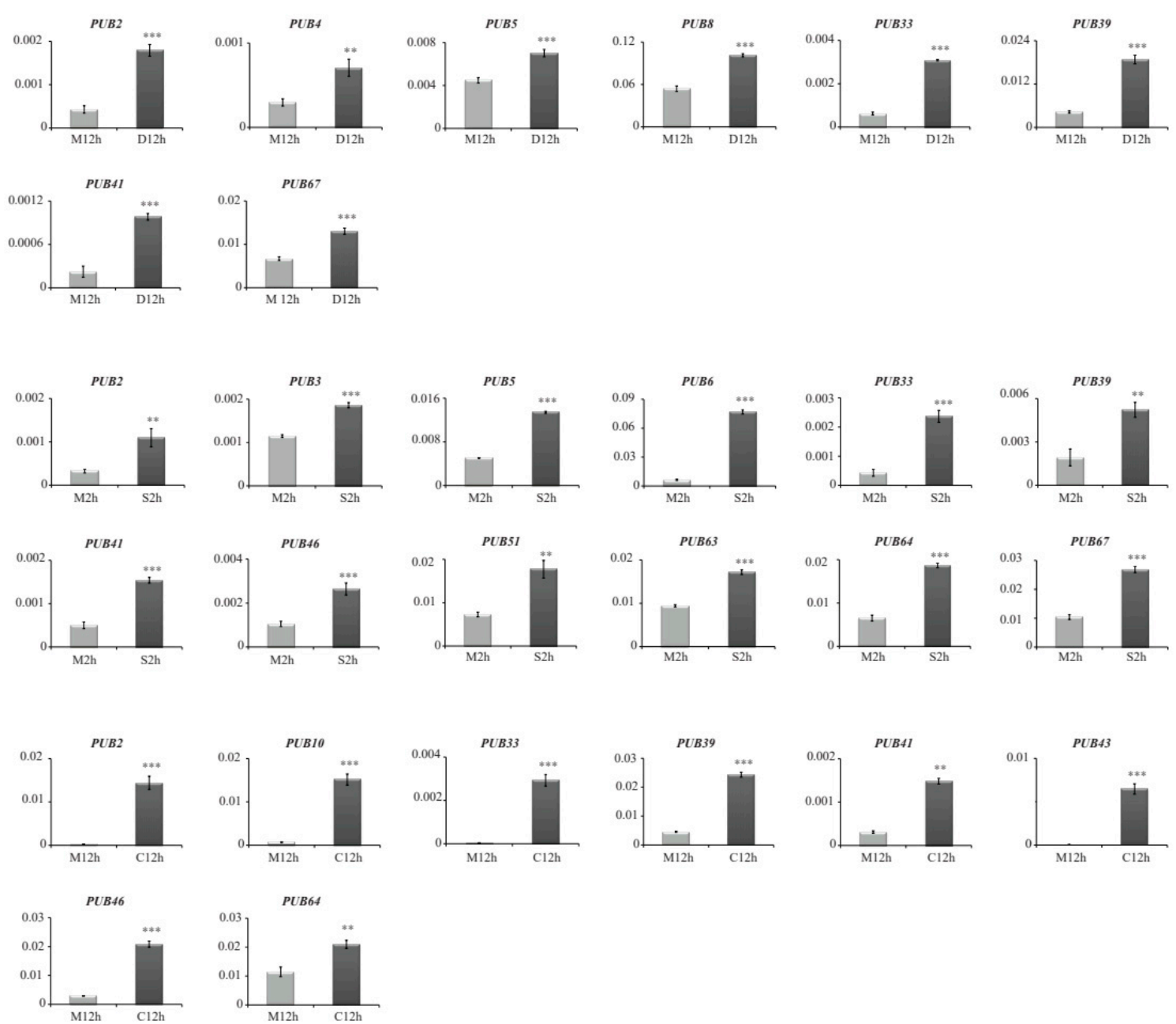

Figure 2. qRT expression profiles for 16 OsPUB genes selected from global transcriptome data analysis. OsDREB1A and OsbZIP23 were used as marker genes for abiotic stress (A). Abiotic stress samples were prepared from drought (B), salinity (C), and cold (D) $(0,2,6$, and $12 \mathrm{~h})$ in root or leaf. Rice ubiquitin (OsUbi5) was served as internal control. ${ }^{* *} p$ value $<0.01 ;{ }^{* * *} p$ value $<0.001 . \mathrm{N}=3$. 


\subsection{PUB Family Genes Are Involved in OsGI Mediating Diurnal Regulation Pathway}

Diurnal rhythm in plants is regulated by light and the circadian clock, and metabolism, physiology, and behavior change between day and night [36]. In addition, recent studies have shown that circadian rhythm correlates with abiotic stress [37-39]. To identify the PUB genes in rice associated with diurnal rhythm, we analyzed expression patterns using publicly available Agilent 44k array data (GSE36040) obtained in rice leaves harvested under diurnal rhythm in nine different developmental stages [40]. Of the 77 PUB genes, nine (OsPUB2, OsPUB4, OsPUB16, OsPUB20, OsPUB34, OsPUB47, OsPUB52, OsPUB63, and OsPUB77) genes were observed to show diurnal rhythm in the leaves (Figure S1). Among the 16 genes with increased expression in Abiotic stress, three (OsPUB2, OsPUB4, and OsPUB63) genes were associated with diurnal rhythm (Figure 1). To confirm expression associated with diurnal rhythm, 37-day-old leaves were sampled at $2 \mathrm{~h}$ intervals for $24 \mathrm{~h}$, and we confirm that diurnal rhythms of OsPUB4 and OsPUB63 were observed through Real-Time qPCR analyses. There was no difference in expression in the dark state of OsPUB4, but expression increased when the plant first recognized the light (Figure 3). In contrast, OsPUB63 showed no expression difference in the light state but increased expression in the dark state (Figure 3). Unfortunately, OsPUB2 was associated with diurnal rhythms in the Agilent 44k array data, but no significant change in expression was observed in Real-Time qPCR analysis (Figure S2).

To obtain the insight into the mechanism on the regulation of the diurnal rhythm of these PUB genes, we used rice gi mutants with defects in the diurnal rhythm [27]. In osgi, diurnal expression of a well-known marker gene for diurnal rhythm, LATE ELONGATED HYPOCOTYL (LHY) [41], was dramatically down-regulated across all time points (Figure 3B). Interestingly, OsPUB4, like LHY, disappeared from diurnal rhythm expression patterns in osgi mutants (Figure 3B). In contrast, OsPUB63 was able to observe the same diurnal rhythm expression patterns in both the control (dongjin) and osgi mutants. These results indicate that the OsPUB4 gene is involved to the OsGI-mediating diurnal rhythm regulating mechanism.

A $\log _{2}$ intensity value

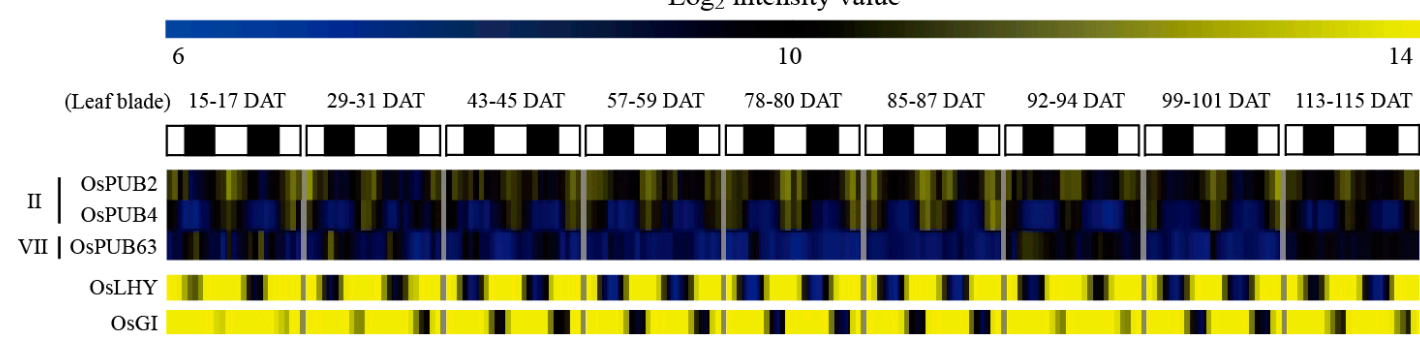

B
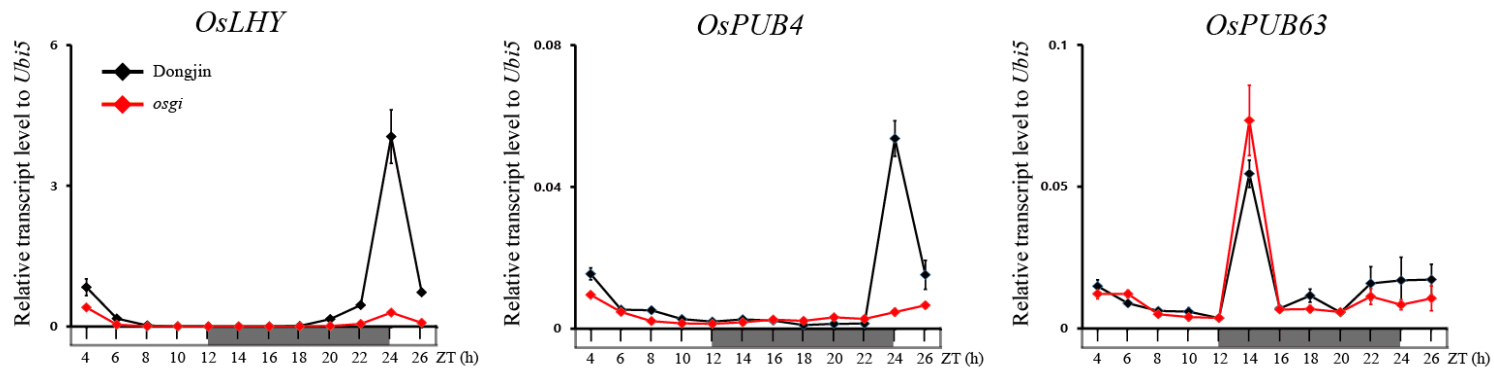

Figure 3. Diurnal expression patterns of two OSPUB genes in mature leaves, using available Agilent $44 \mathrm{k}$ array data over the entire plant life span (A), or evaluated at 12 time points over 24-h period in "Dongjin" rice and osgi mutant (B). OsLHY was standard marker gene for diurnal rhythm. OsUbi5 was served as the internal control. The continuous white and black bars indicate day and night time, respectively. $\mathrm{ZT}$, zeitgeber time ( $\mathrm{ZT}=0$ at lights-on). 


\subsection{OsPUB4 Is Under the Control of OsGI, One of Main Regulators of the Circadian Clock}

GI is involved in maintaining the circadian clock of downstream genes. It has been reported that the circadian rhythms of flowering regulatory genes such as Ehd1 (Early heading date 1), Hd3a (Heading date 3a), RFT1 (RICE FLOWERING LOCUS T 1), Hd1 (Heading date 1) and OsMADS51 are significantly reduced in osgi mutants $[27,42,43]$. Interestingly, like the flowering regulation genes mentioned earlier, the circadian rhythm of OsPUB4 also decreases in the osgi mutant (Figure 3). This result indicates that OsPUB4 might be under the control of OsGI, one of the main regulators of the circadian clock. We created a putative network on the STRING website (https://string-db.org/cgi/ input.pl?sessionId=dsUIDFue7qrX\&input_page_show_search=on) to check the correlation between OsPUB4 and OsGI. As expected, the network includes photoreceptors such as PHYA (Phytochrome A), PHYB (Phytochrome B), and transcription factors related to flowering time such as Ghd7 (Grain number, plant height, and heading date7), HD3A and HD2 (Figure 4).
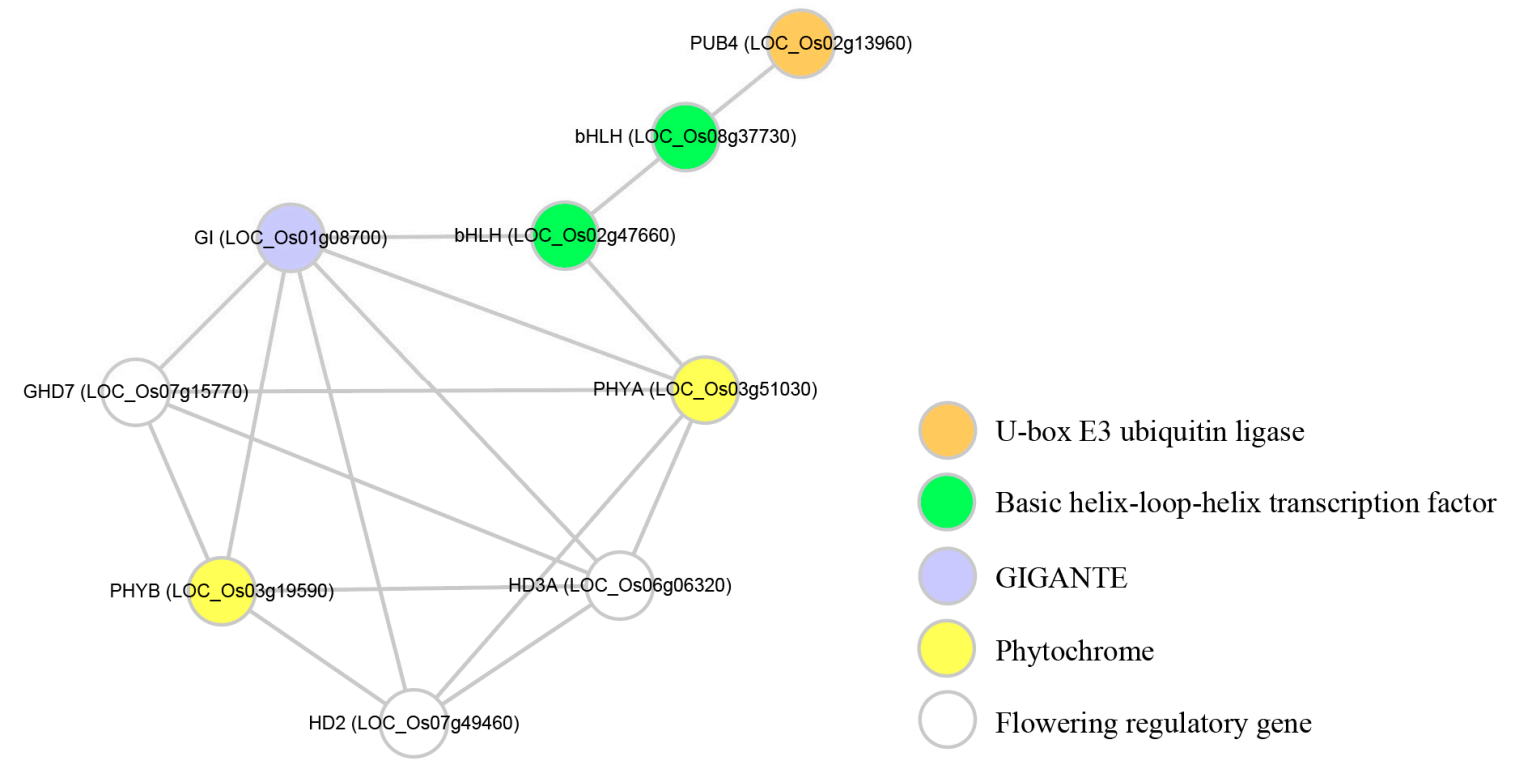

Figure 4. Construction of predicted protein-protein interaction networks associated with OsPUB4 and OsGI. Using the STRING tool, we found seven proteins that are expected to interact with OsPUB4 (orange circle) and OsGI (blue circle). Three of the seven proteins were identified as flowering regulatory genes (White circles), two as phytochrome (yellow circles), and two as bHLH TF (green circles).

\section{Conclusions}

In this study, we selected genes that respond to abiotic stress in the OsPUB family, and further confirmed their circadian clock. Recent studies have shown that genes associated with the circadian clock and flowering time are associated with abiotic stress [38,39]. For example, in Arabidopsis, the GI-overexpressed transgenic plants show increased salt sensitivity, while the osgi mutants show a salt tolerance phenotype [44]. In addition, LOV KELCH protein 2 (LKP2), which regulates circadian rhythm and flowering time in plants, increases dehydration tolerance when overexpressed [45]. The key clock component (TOC1, the timing of CAB expression 1) that binds to the promoter of the ABA-related gene increases drought tolerance in toc1-RNAi plants. Conversely, overexpression of TOC1 increases water loss in drought conditions, leading to a decrease in survival rate [46]. Interestingly, there is no correlation between the effects of mutations on clock function and abiotic stress resistance. Instead, changes in the expression level of the clock gene in the mutants are presumed to have a direct effect on the regulation of the abiotic stress response [38]. For example, half of the genes responsive to drought, salinity, heat, and osmoticum were found to have diurnal rhythm [47]. This transcriptomic analysis suggests that many genes that respond to abiotic stress are under the control of the circadian clock. 
Therefore, we speculate that OsPUB4 will play a role similar to COP1 (Constitutive photomorphogenic 1). COP1 is an E3 ubiquitin ligase containing RING-finger and WD40 domains, and is known to be involved in the control of seedling development, flowering time, and circadian rhythm [48]. In particular, HY5 (Long hypocotyl 5), PHYA, PHYB, PIL1 (Phytochrome interacting factor 3-like 1), CO (CONSTANS), GI (GIGANTEA), etc. were identified as substrates of COP1 [49-54]. Accordingly, we expect OsPUB4 to participate in circadian rhythms and abiotic stress responses by controlling the stability of various proteins.

Supplementary Materials: The following are available online at http://www.mdpi.com/2223-7747/9/9/1071/s1, Figure S1: Heat-map expression data associated with the diurnal rhythm of the OsPUB family genes. Figure S2: Diurnal expression patterns of OsPUB2 gene evaluated at 12 time points over 24-h period in "Dongjin" rice and osgi mutant. Table S1: Summary of primer sequences used for qRT-PCR analyses of this study.

Author Contributions: Conceptualization, Y.-H.Y.; Formal analysis, Y.-H.Y.; Investigation, X.J.; Supervision, K.-H.J.; Writing — original draft, Y.-H.Y.; Writing—review \& editing, K.-H.J. All authors have read and agreed to the published version of the manuscript.

Funding: This work was supported by grants from the Next-Generation BioGreen 21 Program (PJ01325901 and PJ01366401 to KHJ) and a Program (PJ01492703 to JKH), the Rural Development Administration, Korea.

Acknowledgments: We thank Gynheung An for providing valuable advice at all times.

Conflicts of Interest: There is no conflict of interest to declare.

\section{References}

1. Vierstra, R.D. The ubiquitin-26S proteasome system at the nexus of plant biology. Nat. Rev. Mol. Cell Biol. 2009, 10, 385-397. [CrossRef] [PubMed]

2. Santner, A.; Estelle, M. The ubiquitin-proteasome system regulates plant hormone signaling. Plant J. 2010, 61, 1029-1040. [CrossRef] [PubMed]

3. Stone, S.L. The role of ubiquitin and the $26 \mathrm{~S}$ proteasome in plant abiotic stress signaling. Front. Plant Sci. 2014, 5, 135. [CrossRef] [PubMed]

4. Smalle, J.; Vierstra, R.D. The ubiquitin $26 S$ proteasome proteolytic pathway. Annu. Rev. Plant Biol. 2004, 55, 555-590. [CrossRef]

5. Pickart, C.M.; Eddins, M.J. Ubiquitin: Structures, functions, mechanisms. Biochim. Biophys. Acta-Mol. Cell Res. 2004, 1695, 55-72. [CrossRef]

6. Lee, J.H.; Kim, W.T. Regulation of abiotic stress signal transduction by E3 ubiquitin ligases in arabidopsis. Mol. Cells 2011, 31, 201-208. [CrossRef]

7. Koegl, M.; Hoppe, T.; Schlenker, S.; Ulrich, H.D.; Mayer, T.U.; Jentsch, S. A Novel Ubiquitination Factor, E4, Is Involved in Multiubiquitin Chain Assembly. Cell 1999, 96, 635-644. [CrossRef]

8. Hatakeyama, S.; Nakayama, K.I. U-box proteins as a new family of ubiquitin ligases. Biochem. Biophys. Res. Commun. 2003, 302, 635-645. [CrossRef]

9. Wiborg, J.; O'Shea, C.; Skriver, K. Biochemical function of typical and variant Arabidopsis thaliana U-box E3 ubiquitin-protein ligases. Biochem. J. 2008, 413, 447-457. [CrossRef]

10. Zeng, L.R.; Park, C.H.; Venu, R.C.; Gough, J.; Wang, G.L. Classification, expression pattern, and E3 Ligase Activity Assay of Rice U-box-containing proteins. Mol. Plant 2008, 1, 800-815. [CrossRef]

11. McClung, C.R. Plant Circadian Rhythms. Plant Cell Online 2006. [CrossRef] [PubMed]

12. Harmer, S.L. The Circadian System in Higher Plants. Annu. Rev. Plant Biol. 2009. [CrossRef] [PubMed]

13. Dunlap, J.C. Molecular bases for circadian clocks. Cell 1999, 96, 271-290. [CrossRef]

14. Suárez-López, P.; Wheatley, K.; Robson, F.; Onouchi, H.; Valverde, F.; Coupland, G. CONSTANS mediates between the circadian clock and the control of flowering in Arabidopsis. Nature 2001, 410, 1116-1120. [CrossRef] [PubMed]

15. Sawa, M.; Nusinow, D.A.; Kay, S.A.; Imaizumi, T. FKF1 and GIGANTEA complex formation is required for day-length measurement in Arabidopsis. Science 2007, 318, 261-265. [CrossRef]

16. Byun, M.Y.; Cui, L.H.; Oh, T.K.; Jung, Y.-J.; Lee, A.; Park, K.Y.; Kang, B.G.; Kim, W.T. Homologous U-box E3 Ubiquitin Ligases OsPUB2 and OsPUB3 Are Involved in the Positive Regulation of Low Temperature Stress Response in Rice (Oryza sativa L.). Front. Plant Sci. 2017, 8, 16. [CrossRef] 
17. Zeng, L.R.; Qu, S.; Bordeos, A.; Yang, C.; Baraoidan, M.; Yan, H.; Xie, Q.; Nahm, B.H.; Leung, H.; Wang, G. Spotted leaf11, A Negative Regulator of Plant Cell Death and Defense, Encodes a U-Box/Armadillo Repeat Protein Endowed with E3 Ubiquitin Ligase Activity. Plant Cell 2004, 16, 2795-2808. [CrossRef]

18. Park, J.J.; Yi, J.; Yoon, J.; Cho, L.H.; Ping, J.; Jeong, H.J.; Cho, S.K.; Kim, W.T.; An, G. OsPUB15, an E3 ubiquitin ligase, functions to reduce cellular oxidative stress during seedling establishment. Plant J. 2011, 65, $194-205$. [CrossRef]

19. Ishikawa, K.; Yamaguchi, K.; Sakamoto, K.; Yoshimura, S.; Inoue, K.; Tsuge, S.; Kojima, C.; Kawasaki, T. Bacterial effector modulation of host E3 ligase activity suppresses PAMP-triggered immunity in rice. Nat. Commun. 2014, 5, 5430. [CrossRef]

20. Hu, X.; Qian, Q.; Xu, T.; Zhang, Y.; Dong, G.; Gao, T.; Xie, Q.; Xue, Y. The U-Box E3 Ubiquitin Ligase TUD1 Functions with a Heterotrimeric G $\alpha$ Subunit to Regulate Brassinosteroid-Mediated Growth in Rice. PLoS Genet. 2013, 9, e1003391. [CrossRef]

21. Jung, K.-H.; Cao, P.; Sharma, R.; Jain, R.; Ronald, P.C. Phylogenomics databases for facilitating functional genomics in rice. Rice 2015, 8, 26. [CrossRef] [PubMed]

22. Ohyanagi, H. The Rice Annotation Project Database (RAP-DB): Hub for Oryza sativa ssp. japonica genome information. Nucleic Acids Res. 2005, 34, D741-D744. [CrossRef] [PubMed]

23. Higgins, D.G.; Thompson, J.D.; Gibson, T.J. Using CLUSTAL for multiple sequence alignments. Methods Enzymol. 1996, 266, 383-402. [PubMed]

24. Tamura, K.; Peterson, D.; Peterson, N.; Stecher, G.; Nei, M.; Kumar, S. MEGA5: Molecular evolutionary genetics analysis using maximum likelihood, evolutionary distance, and maximum parsimony methods. Mol. Biol. Evol. 2011, 28, 2731-2739. [CrossRef]

25. Yoo, Y.-H.; Chandran, A.K.N.; Park, J.-C.; Gho, Y.-S.; Lee, S.-W.; An, G.; Jung, K.-H. OsPhyB-Mediating Novel Regulatory Pathway for Drought Tolerance in Rice Root Identified by a Global RNA-Seq Transcriptome Analysis of Rice Genes in Response to Water Deficiencies. Front. Plant Sci. 2017, 8, 580. [CrossRef] [PubMed]

26. Chandran, A.K.N.; Kim, J.W.; Yoo, Y.H.; Park, H.L.; Kim, Y.J.; Cho, M.H.; Jung, K.H. Transcriptome analysis of rice-seedling roots under soil-salt stress using RNA-Seq method. Plant Biotechnol. Rep. 2019, 13, 567-578. [CrossRef]

27. Lee, Y.S.; An, G. OsGI controls flowering time by modulating rhythmic flowering time regulators preferentially under short day in rice. J. Plant Biol. 2015, 58, 137-145. [CrossRef]

28. Yoo, Y.-H.; Choi, H.-K.; Jung, K.-H. Genome-wide identification and analysis of genes associated with lysigenous aerenchyma formation in rice roots. J. Plant Biol. 2015, 58, 117-127. [CrossRef]

29. Yu, G.H.; Huang, S.H.; He, R.; Li, Y.Z.; Cheng, X.G. Transgenic Rice Overexperessing a Tomato Mitochondrial Phosphate Transporter, SIMPT3;1, Promotes Phosphate Uptake and Increases Grain Yield. J. Plant Biol. 2018, 61, 383-400. [CrossRef]

30. Jain, M.; Nijhawan, A.; Tyagi, A.K.; Khurana, J.P. Validation of housekeeping genes as internal control for studying gene expression in rice by quantitative real-time PCR. Biochem. Biophys. Res. Commun. 2006, 345, 646-651. [CrossRef]

31. Szklarczyk, D.; Morris, J.H.; Cook, H.; Kuhn, M.; Wyder, S.; Simonovic, M.; Santos, A.; Doncheva, N.T.; Roth, A.; Bork, P.; et al. The STRING database in 2017: Quality-controlled protein-protein association networks, made broadly accessible. Nucleic Acids Res. 2017. [CrossRef] [PubMed]

32. Su, G.; Morris, J.H.; Demchak, B.; Bader, G.D. Biological Network Exploration with Cytoscape 3. Curr. Protoc. Bioinform. 2014, 47, 8-13. [CrossRef] [PubMed]

33. Li, Y.; Luo, C.; Chen, Y.; Xiao, X.; Fu, C.; Yang, Y. Transcriptome-based Discovery of AP2/ERF tRanscription Factors and Expression Profiles Under Herbivore Stress Conditions in Bamboo (Bambusa emeiensis). J. Plant Biol. 2019, 62, 297-306. [CrossRef]

34. Dubouzet, J.G.; Sakuma, Y.; Ito, Y.; Kasuga, M.; Dubouzet, E.G.; Miura, S.; Seki, M.; Shinozaki, K.; Yamaguchi-Shinozaki, K. OsDREB genes in rice, Oryza sativa L., encode transcription activators that function in drought-, high-salt- and cold-responsive gene expression. Plant J. 2003, 33, 751-763. [CrossRef] [PubMed]

35. Xiang, Y.; Tang, N.; Du, H.; Ye, H.; Xiong, L. Characterization of OsbZIP23 as a Key Player of the Basic Leucine Zipper Transcription Factor Family for Conferring Abscisic Acid Sensitivity and Salinity and Drought Tolerance in Rice. Plant Physiol. 2008, 148, 1938-1952. [CrossRef]

36. McClung, R.C. Plant Circadian Rhythms. Plant Cell 2006, 18, 792-803. [CrossRef] 
37. Sanchez, A.; Shin, J.; Davis, S.J. Abiotic stress and the plant circadian clock. Plant Signal. Behav. 2011, 6, 223-231. [CrossRef]

38. Grundy, J.; Stoker, C.; Carré, I.A. Circadian regulation of abiotic stress tolerance in plants. Front. Plant Sci. 2015, 6, 648. [CrossRef]

39. Seo, P.J.; Mas, P. STRESSing the role of the plant circadian clock. Trends Plant Sci. 2015, 20, 230-237. [CrossRef]

40. Sato, Y.; Takehisa, H.; Kamatsuki, K.; Minami, H.; Namiki, N.; Ikawa, H.; Ohyanagi, H.; Sugimoto, K.; Antonio, B.A.; Nagamura, Y. RiceXPro Version 3.0: Expanding the informatics resource for rice transcriptome. Nucleic Acids Res. 2013, 41. [CrossRef]

41. Ogiso, E.; Takahashi, Y.; Sasaki, T.; Yano, M.; Izawa, T. The Role of Casein Kinase II in Flowering Time Regulation Has Diversified during Evolution. Plant Physiol. 2010, 152, 808-820. [CrossRef]

42. Izawa, T.; Mihara, M.; Suzuki, Y.; Gupta, M.; Itoh, H.; Nagano, A.J.; Motoyama, R.; Sawada, Y.; Yano, M.; Hirai, M.Y.; et al. Os- GIGANTEA Confers Robust Diurnal Rhythms on the Global Transcriptome of Rice in the Field. Plant Cell 2011, 23, 1741-1755. [CrossRef]

43. Cho, L.H.; Pasriga, R.; Yoon, J.; Jeon, J.S.; An, G. Roles of Sugars in Controlling Flowering Time. J. Plant Biol. 2018, 61, 121-130. [CrossRef]

44. Kim, W.Y.; Ali, Z.; Park, H.J.; Park, S.J.; Cha, J.Y.; Perez-Hormaeche, J.; Quintero, F.J.; Shin, G.; Kim, M.R.; Qiang, Z.; et al. Release of SOS2 kinase from sequestration with GIGANTEA determines salt tolerance in Arabidopsis. Nat. Commun. 2013, 4, 1-13. [CrossRef]

45. Miyazaki, Y.; Abe, H.; Takase, T.; Kobayashi, M.; Kiyosue, T. Overexpression of LOV KELCH PROTEIN 2 confers dehydration tolerance and is associated with enhanced expression of dehydration-inducible genes in Arabidopsis thaliana. Plant Cell Rep. 2015, 34, 843-852. [CrossRef] [PubMed]

46. Legnaioli, T.; Cuevas, J.; Mas, P. TOC1 functions as a molecular switch connecting the circadian clock with plant responses to drought. EMBO J. 2009, 28, 3745-3757. [CrossRef] [PubMed]

47. Covington, M.F.; Maloof, J.N.; Straume, M.; Kay, S.A.; Harmer, S.L. Global transcriptome analysis reveals circadian regulation of key pathways in plant growth and development. Genome Biol. 2008, 9, R130. [CrossRef] [PubMed]

48. Kim, J.Y.; Jang, I.C.; Seo, H.S. COP1 controls abiotic stress responses by modulating AtSIZ1 function through its E3 ubiquitin ligase activity. Front. Plant Sci. 2016, 7, 1182. [CrossRef]

49. Osterlund, M.T.; Hardtke, C.S.; Ning, W.; Deng, X.W. Targeted destabilization of HY5 during light-regulated development of Arabidopsis. Nature 2000, 405, 462-466. [CrossRef] [PubMed]

50. Soo Seo, H.; Yang, J.Y.; Ishikawa, M.; Bolle, C.; Ballesteros, M.L.; Chua, N.H. LAF1 ubiquitination by COP1 controls photomorphogenesis and is stimulated by SPA1. Nature 2003, 423, 995-999. [CrossRef]

51. Seo, H.S.; Watanabe, E.; Tokutomi, S.; Nagatani, A.; Chua, N.H. Photoreceptor ubiquitination by COP1 E3 ligase desensitizes phytochrome A signaling. Genes Dev. 2004, 18, 617-622. [CrossRef] [PubMed]

52. Luo, Q.; Lian, H.L.; He, S.B.; Li, L.; Jia, K.P.; Yang, H.Q. COP1 and phyB physically interact with PIL1 to regulate its stability and photomorphogenic development in Arabidopsis. Plant Cell 2014, 26, 2441-2456. [CrossRef]

53. Jang, S.; Marchal, V.; Panigrahi, K.C.S.; Wenkel, S.; Soppe, W.; Deng, X.W.; Valverde, F.; Coupland, G. Arabidopsis COP1 shapes the temporal pattern of $\mathrm{CO}$ accumulation conferring a photoperiodic flowering response. EMBO J. 2008, 27, 1277-1288. [CrossRef] [PubMed]

54. Yu, J.W.; Rubio, V.; Lee, N.Y.; Bai, S.; Lee, S.Y.; Kim, S.S.; Liu, L.; Zhang, Y.; Irigoyen, M.L.; Sullivan, J.A.; et al. COP1 and ELF3 Control Circadian Function and Photoperiodic Flowering by Regulating GI Stability. Mol. Cell 2008, 32, 617-630. [CrossRef] [PubMed]

(C) 2020 by the authors. Licensee MDPI, Basel, Switzerland. This article is an open access article distributed under the terms and conditions of the Creative Commons Attribution (CC BY) license (http://creativecommons.org/licenses/by/4.0/). 